\section{Fatores associados a disposição de consumidores em adquirir carne bovina com certificação de origem na cidade do Rio de Janeiro, Brasil}

\author{
Factors associated with consumer provision to buy beef with \\ origin certification, Rio de Janeiro, Brazil
}

\author{
Marcos Aurélio Lopes ${ }^{1 *}$, Danielle Rodrigues Magalhães², Peter Bitencourt Faria ${ }^{3}$, Fábio Raphael Pascoti Bruhn4, \\ Stela Márcia Pereira ${ }^{5}$ \& Fabiana Alves Demeu ${ }^{6,7}$ \\ 'Licenciado em Ciências Agrícolas, Dsc. Universidade Federal de Lavras - UFLA, Lavras, MG, Brasil \\ ZZootecnista, Msc. Programa de Pós-graduação em Ciências Veterinárias, Universidade Federal de Lavras - UFLA, Lavras, MG, \\ Brasil \\ ${ }^{3}$ Médico veterinário, Dsc. Universidade Federal de Lavras - UFLA, Lavras, MG, Brasil \\ ${ }^{4}$ Médico veterinário, Dsc. Universidade Federal de Pelotas - UFPe, Pelotas, RS, Brasil \\ 5Odontóloga, Dsc. Universidade Federal de Lavras - UFLA, Lavras, MG, Brasil \\ 'Zootecnista. Instituto Federal de Rondônia, Ariquemes, RO, Brasil \\ 7Doutoranda. Programa de Pós-graduação em Ciências Veterinárias, Universidade Federal de Lavras - UFLA, Lavras, MG, Brasil
}

\section{Resumo}

Objetivou-se verificar a influência dos fatores socioeconômicos na disposição de 400 consumidores, do município do Rio de Janeiro, RJ, em adquirir carne bovina com certificação de origem e verificar as características inerentes ao produto que auxiliam o consumidor no momento da compra. Foi realizada uma análise descritiva de todas as variáveis e, posteriormente, realizado a análise univariada por teste qui-quadrado $\left(\mathrm{X}^{2}\right)$. As variáveis foram adicionadas no modelo múltiplo da regressão logística Generalized Estimating Equations (GEE) e, para todas as variáveis presentes no modelo final ( $\mathrm{x} \leq 0,05$ ), foi calculado o risco por meio da Odds Ratio (OR) ajustada a um intervalo de confiança de $95 \%$. Os fatores socioeconômicos influenciaram a disposição dos consumidores do Rio de Janeiro em adquirir carne bovina com certificação de origem. Os entrevistados estão dispostos a comprar carne rastreada, sendo em sua maioria consumidores com renda acima de sete salários mínimos; e estão dispostos a pagar até $5 \%$ a mais por esse produto. Os atributos intrínsecos mais importantes na tomada de decisão no momento da compra da carne foram a cor, maciez e textura da carne, odor e a pouca quantidade de gordura. A maioria dos consumidores do Rio de Janeiro nunca ouviu falar sobre carne rastreada ou com certificação de origem. Um dos benefícios citados pela maioria dos consumidores com menor escolaridade é que a carne rastreada tem mais qualidade, é mais saborosa e nutritiva. A desvantagem relatada pela maioria das mulheres é que a carne com certificação acarreta uma supervalorização. Porém, os entrevistados estão dispostos a pagar até $10 \%$ a mais pelo produto.

Palavras-chave: atributos da carne, certificação de origem, rastreabilidade, rótulo, segurança alimentar.

\begin{abstract}
The present study aimed to verify the influence of socioeconomic factors in the disposition of 400 consumers, from the city of Rio de Janeiro, RJ in purchasing beef with certification of origin and to verify the inherent characteristics of the product that help the consumer at the time of purchase, considering their prior knowledge about traceability and certification of origin. A descriptive analysis of all variables was performed and subsequently conducted univariate analysis by chi-square $\left(\mathrm{x}^{2}\right)$ test. The variables were added in the Generalized Estimating Equations (GEE) multiple logistic regression model, and for all variables in the final model $(\mathrm{p} \leq 0.05)$ was calculated by the risk odds ratio (OR) adjusted to a range of $95 \%$ confidence. The respondents are willing to buy traced flesh, being mostly consumers with income above seven minimum wages; and are willing to pay up to $5 \%$ more for this product. The most important intrinsic attributes in the decision when buying meat were the color, softness, and texture of meat, odor and little amount of fat. Most consumers of Rio de Janeiro never heard of meat with certification of origin or screened more quality, more flavorful and nutritious. One of the benefits cited by the majority of consumers with less education is that certificated meat has screened more quality,
\end{abstract}

\section{B] M \\ Brazilian Journal of Veterinary Medicine}

p-ISSN 0100-2430
Como citar: Lopes, M. A., Magalhães, D. R., Faria, P. B., Bruhn, F. R. P., Pereira, S. M., \& Demeu F. A. (2017). Fatores associados a disposição de consumidores em adquirir carne bovina com certificação de origem na cidade do Rio de Janeiro, Brasil. Brazilian Journal of Veterinary Medicine,39(2), 100-110. doi: 10.29374/2527-2179. bjvm027117

Fonte de financiamento: MAL é bolsista de Produtividade CNPq, FAD é bolsista pro doutoral CAPES.

Conflito de interesses: Os autores declaram não haver conflito de interesses que precisam ser informados.

Recebido: Janeiro 27, 2016

Aceito: Agosto 05, 2016.

Oestudo foi realizado pela Universidade Federal de Lavras - UFLA, Rio de Janeiro, RJ, Brasil.

\section{*Correspondência}

Marcos Aurélio Lopes

Laboratório de Informática Aplicada, Departamento de Medicina Veterinária, Universidade Federal de Lavras - UFLA, Campus UFLA

CEP 37200-000 - Lavras (MG), Brasil

E-mail:malopes@dmv.ufla.br 
more flavorful and nutritious. The disadvantage reported by most women is that meat with certification entails an overvaluation of beef. However, respondents are willing to buy meat traced, being mostly male consumers; and are willing to pay up to $10 \%$ more for the product.

Keywords: meat attributes, certification of origin, traceability, label, food safety.

\section{Introdução}

Rastreabilidade é o sistema de controle de animais que permite sua identificação individual desde o nascimento até o abate, registrando todas as ocorrências relevantes ao longo de sua vida, a origem exata do produto, com os vários fatores que incorporam seu desenvolvimento; o histórico dos processos aplicados ao produto; a distribuição e a localização do produto acabado (Lopes \& Santos, 2007). Ela é necessária para assegurar a garantia de origem de um produto e mostrar que o mesmo foi produzido dentro das legislações vigentes para esse fim, e, portanto, apto a receber seu certificado de origem. Com essa garantia, o consumidor adquire confiabilidade em todo o sistema, possibilitando maior valor agregado do produto.

Segundo Furquim \& Cyrillo (2012), o sistema de rastreabilidade surgiu como uma medida de assegurar transparência em toda a cadeia produtiva e contribuir para a segurança alimentar. Tal fato se deu após o surgimento da Bovine Spongiform Encephalopathy (BSE), ou doença da "vaca louca", na Inglaterra em 1996. A Associação Brasileira das Indústrias Exportadoras de Carne (Associação Brasileira das Indústrias Exportadoras de Carnes, 2011) relatou que, dessa forma, a rastreabilidade bovina não foi criada somente para atender a uma barreira protecionista dos mercados consumidores, mas sim, uma ferramenta para melhorar a segurança alimentar e a garantia ao consumidor.

As informações de origem da carne podem incentivar o produtor na tomada de decisão da aquisição do produto. Por isso, a consolidação do sistema de rastreabilidade é essencial para os consumidores. Porém, a oferta de carne com certificação no mercado varejista ainda é pequena, o que causa a falta de incentivo de adesão dos pecuaristas ao programa de rastreabilidade brasileiro (Lopes \& Santos, 2007).

Para que ocorra a expansão do mercado da carne rastreada, no Brasil, é preciso verificar a disposição dos consumidores em adquirir a carne com certificação e analisar o seu conhecimento com relação aos conceitos sobre rastreabilidade e certificação de origem, pois é necessário conhecimento sobre a importância da carne com certificação para a promoção de um aumento na procura por esse produto. É preciso, ainda, verificar a disposição dos consumidores em pagar mais por ter "garantia" de melhor qualidade.

Diversos aspectos da rastreabilidade bovina tem sido estudados por vários pesquisadores. No entanto, quando se trata de do consumo de carne rastreada, ou certificada, poucas pesquisas tem sido realizadas no país. Assim, o objetivo deste trabalho foi o de analisar a influência dos fatores socioeconômicos na disposição de consumidores em adquirir carne bovina com certificação de origem e verificar as características inerentes ao produto que os auxiliam no momento da compra, considerando o seu conhecimento prévio sobre rastreabilidade e certificação de origem. Especificamente, pretendeu-se, ainda, concernente aos fatores socioeconômicos dos consumidores a) verificar o consumo de carne com certificação de origem; b) quantificar o nível de conhecimento sobre a rastreabilidade e certificação de origem da carne bovina; c) identificar os principais atributos da carne bovina que influenciam a decisão de compra; d) identificar quais os benefícios e as limitações que a carne com certificação apresenta em relação à carne sem certificação; e) verificar a disposição em pagar mais pela carne com certificação, e f) quantificar o percentual de acréscimo sobre o preço final dessa carne que os consumidores estão dispostos a pagar pela carne rastreada.

\section{Materiais e métodos}

Para avaliar a associação entre a percepção e atitude de consumidores de carne bovina rastreada e algumas características sócio demográficas foi realizado um estudo observacional de corte transversal em quatro supermercados na cidade do Rio de Janeiro, Brasil, em outubro de 2012. A definição do número de entrevistados $(n=400)$ na amostra baseou-se em Barbetta (2007) considerando um erro amostral máximo de 5\% e uma população de 6.320.446 habitantes no Rio de Janeiro (Instituto Brasileiro de Geografia e Estatística, 2010). 
Visando obter informações sobre a caracterização da percepção e atitude de consumidores de carne bovina, foram realizadas entrevistas, a partir de formulário estruturado contendo 36 perguntas, adaptados de Velho et al. (2009) e Lopes et al. (2014). Ainda, para todos os entrevistados, foram obtidas informações sobre características sócio demográficas relacionadas ao sexo, idade (até 40 anos; mais que 40 anos), escolaridade (até segundo grau; graduação ou pós-graduação) e renda (até seis salários mínimos; mais que seis salários mínimos) utilizadas como variáveis independentes no estudo. No período da coleta das informações o salário mínimo correspondia ao valor de $\mathrm{R} \$ 622,00$.

Os entrevistados foram selecionados aleatoriamente, sendo convidados enquanto se encontravam em frente à gôndola de carnes no supermercado. Para os consumidores que nunca haviam ouvido falar sobre carne bovina rastreada, a entrevista se restringia as questões relativas às características sócio demográficas.

Para identificar as características sócio-demográficas associadas à percepção e atitude dos consumidores em relação a carne bovina com certificação de origem foi realizada a análise univariada por teste qui-quadrado $\left(x^{2}\right)$ ou Exato de Fischer. Este último, quando se observou menos que cinco observações no quadrante do teste. As variáveis que mostraram associação com $\mathrm{p} \leq 0,2$ pelos testes mencionados foram selecionadas para a construção do modelo múltiplo (Lopes et al., 2014).

Assim, a existência de associação entre os fatores foi verificada utilizando o modelo múltiplo Generalized Estimating Equations (GEE) de regressão logística, que é mais adequada quando se observa dados associados em diferentes dimensões (Hanley et al., 2003). A análise GEE permite a avaliação de associação de múltiplos indivíduos considerando o supermercado como sujeito no modelo, assumindo que os casos são dependentes dentro de cada sujeito e independentes entre sujeitos. Para todas as variáveis presentes no modelo final $(p<0,05)$, foi estimado o risco por meio da Odds Ratio (OR) ajustada e seu intervalo de confiança de 95\%.

\section{Resultados}

Os 400 consumidores entrevistados em quatro supermercados que comercializam carne com garantia de origem, no município do Rio de Janeiro, RJ, 125 (31,25\%) conheciam sobre rastreabilidade, carne rastreada ou certificação de origem, e 61 (48,80\%) afirmaram que consomem carne bovina com certificação de origem. A maior parte dos consumidores entrevistados era do sexo feminino (59,25\%), com até 40 anos de idade (68,75\%), renda de até seis salários mínimos (68,42\%) e apresentavam escolaridade de até segundo grau completo (58,20\%). Do total de entrevistados, $58(14,50 \%)$ não quiseram responder sua renda familiar e três $(0,75 \%)$ não informaram o grau de escolaridade. Dentre aqueles que conheciam sobre certificação de origem 17 (13,60\%) não responderam sua renda familiar e $(0,80 \%)$ não informou a escolaridade.

Em relação ao gênero, indivíduos do gênero masculino demonstraram maior conhecimento sobre o termo carne com rastreabilidade, uma vez que $41,7 \%$ destes já tinham ouvido falar em carne rastreada, enquanto apenas $25,1 \%$ dos indivíduos de gênero feminino conheciam este tipo de produto. Do percentual de homens que conhecem carne bovina rastreada, ou com certificação de origem, 50,00\% deles consomem produtos animais com certificação de origem (Tabela 1). Quanto ao conceito de carne rastreada, a minoria (10,29\%) dos homens e 29,82\% das mulheres entenderam ser o conceito correto de rastreabilidade a carne que não possui contaminantes ou resíduos químicos. As mulheres entrevistadas, nesta pesquisa, têm 3,486 mais chances do que os homens de acharem que o conceito correto de rastreabilidade é a carne que não possuem contaminantes ou resíduos químicos (Tabela 1).

Em relação a aceitação em pagar mais caro pela carne rastreada, foi constatado que os homens (33,34\%) estão dispostos a pagar até10\% a mais pela carne com certificação de origem. As chances dos entrevistados do sexo feminino acharem que uma desvantagem de carne certificada é sua supervalorização são 2,539 vezes maiores do que os homens; com isso, a chance das mulheres pagarem até $10 \%$ a mais pela carne certificada é menor $(0,243)$ do que a disposição dos homens pagarem esse valor a mais pela carne certificada (Tabela 1).

Em relação aos atributos mais importantes no momento da compra, os atributos intrínsecos mais importantes foram a cor para 93,33\% das mulheres e 80,95\% dos homens; em seguida, a maciez e textura da carne para 89,17\% dos consumidores do sexo feminino e 77,78\% do sexo 
Tabela 1. Questões sobre o consumo de carne bovina por consumidores que conhecem o termo carne rastreada associadas ao sexo, em quatro supermercados do Rio de Janeiro, RJ, Brasil, em outubro de 2012.

\begin{tabular}{|c|c|c|c|c|c|c|c|}
\hline \multirow{2}{*}{ Questão levantada ${ }^{\mathrm{a}}$} & \multirow{2}{*}{ Sexo } & \multicolumn{2}{|c|}{ Categorias de respostas } & \multirow{2}{*}{ Total } & \multirow{2}{*}{$\mathrm{p}$} & \multirow{2}{*}{ Odds Ratio } & \multirow{2}{*}{ IC (95\%) } \\
\hline & & Não & $\operatorname{Sim}(\%)$ & & & & \\
\hline \multirow{2}{*}{$\begin{array}{l}\text { Já ouviu falar sobre carne rastreada ou com } \\
\text { certificação de origem }\end{array}$} & M & 95 & $68(41,71)$ & 163 & \multirow{2}{*}{0,013} & 1 & \multirow[t]{2}{*}{$0,336-0,881$} \\
\hline & $\mathrm{F}$ & 180 & $57(25,01)$ & 237 & & 0,554 & \\
\hline \multirow{2}{*}{$\begin{array}{l}\text { Consumo de produtos de origem animal } \\
\text { com certificaçãoc }^{c}\end{array}$} & M & 34 & $34(50,00)$ & 68 & \multirow{2}{*}{0,050} & 1 & \multirow[t]{2}{*}{$0,993-4,656$} \\
\hline & $\mathrm{F}$ & 30 & $27(47,37)$ & 57 & & 2,150 & \\
\hline \multirow{2}{*}{$\begin{array}{l}\text { Conceito de rastreabilidade: aquela que não } \\
\text { possui contaminantes ou resíduos químicos }\end{array}$} & M & 61 & $7(10,29)$ & 68 & \multirow{2}{*}{0,012} & 1 & \multirow[t]{2}{*}{$1,317-9,228$} \\
\hline & $\mathrm{F}$ & 40 & $17(29,82)$ & 57 & & 3,486 & \\
\hline \multirow{2}{*}{$\begin{array}{l}\text { Desvantagens da carne com certificação: } \\
\text { supervalorização da carne bovinac }\end{array}$} & M & 52 & $16(23,53)$ & 68 & \multirow{2}{*}{0,017} & 1 & \multirow[t]{2}{*}{$1,180-5,465$} \\
\hline & $\mathrm{F}$ & 32 & $25(43,86)$ & 57 & & 2,539 & \\
\hline \multirow{2}{*}{$\begin{array}{l}\text { Disposto a pagar até } 10 \% \text { a mais pela carne } \\
\text { certficada }^{\mathrm{d}}\end{array}$} & M & 30 & $15(33,34)$ & 45 & \multirow{2}{*}{0,022} & 1 & \multirow[t]{2}{*}{$0,073-0,815$} \\
\hline & $\mathrm{F}$ & 35 & $7(16,67)$ & 42 & & 0,243 & \\
\hline
\end{tabular}

'Regressão logística múltipla estimada por Generalized Estimation Equations; constam apenas os fatores que permaneceram com associação estatisticamente significativa no modelo final $(p \leq 0,05) ;{ }^{b}=400$ - entrevistados; ${ }^{n} n=125$ - apenas aqueles entrevistados que responderam que já tinham ouvido falar em carne rastreada foram considerados no modelo; $\mathrm{d} n=87$ - apenas aqueles entrevistados que responderam que estariam dispostos a pagar mais caro pela carne rastreada foram considerados no modelo.

Tabela 2. Questões sobre o consumo de carne bovina por consumidores que conhecem o termo carne rastreada associadas à idade, em quatro supermercados do Rio de Janeiro, RJ, Brasil, em outubro de 2012.

\begin{tabular}{|c|c|c|c|c|c|c|c|}
\hline \multirow{2}{*}{ Questão levantada ${ }^{a}$} & \multirow{2}{*}{ Idade } & \multicolumn{2}{|c|}{ Categorias de respostas } & \multirow{2}{*}{ Total } & \multirow{2}{*}{$\mathbf{p}$} & \multirow{2}{*}{ Odds Ratio } & \multirow{2}{*}{ IC (95\%) } \\
\hline & & Não & $\operatorname{Sim}(\%)$ & & & & \\
\hline \multirow{2}{*}{$\begin{array}{l}\text { Já ouviu falar sobre carne rastreada ou com } \\
\text { certificação de origem }\end{array}$} & $\leq 40$ anos & 104 & $36(25,71)$ & 140 & \multirow{2}{*}{0,016} & 1 & \multirow[t]{2}{*}{$1,127-3,135$} \\
\hline & $>41$ anos & 171 & $89(34,23)$ & 260 & & 1,879 & \\
\hline \multirow{2}{*}{ Motivo de tomada de decisão da compra: cor $^{c}$} & $\leq 40$ anos & 13 & $23(63,89)$ & 36 & \multirow{2}{*}{0,021} & 1 & \multirow[t]{2}{*}{$1,092-2,978$} \\
\hline & $>41$ anos & 21 & $68(76,40)$ & 89 & & 1,803 & \\
\hline \multirow{2}{*}{$\begin{array}{l}\text { Motivo de tomada de decisão da compra: } \\
\text { pouca quantidade de gordurac }\end{array}$} & $\leq 40$ anos & 17 & $19(52,78)$ & 36 & \multirow{2}{*}{0,000} & 1 & \multirow[t]{2}{*}{$1,519-2,996$} \\
\hline & $>41$ anos & 27 & $62(69,66)$ & 89 & & 2,134 & \\
\hline \multirow{2}{*}{$\begin{array}{l}\text { Motivo de tomada de decisão da compra: } \\
\text { local onde foi abatido (frigorífico) }\end{array}$} & $\leq 40$ anos & 25 & $11(30,56)$ & 36 & \multirow{2}{*}{0,004} & 1 & \multirow[t]{2}{*}{$1,565-9,984$} \\
\hline & $>41$ anos & 41 & $48(53,93)$ & 89 & & 3,953 & \\
\hline
\end{tabular}

Regressão logística múltipla estimada por Generalized Estimation Equations; constam apenas os fatores que permaneceram com associação estatisticamente significativa no modelo final $(p \leq 0,05) ;{ }^{b} n=400$ - entrevistados; ${ }^{c} n=125$ - apenas aqueles entrevistados que responderam que já tinham ouvido falar em carne rastreada foram considerados no modelo.

masculino; também é levado em consideração o odor da carne para 88,33\% das mulheres e $75,40 \%$ dos homens; e, por fim, a pouca quantidade de gordura, que para 67,50\% das mulheres e apenas 32,54\% dos homens é um atributo importante na tomada de decisão no momento da compra. As chances de uma mulher tomar sua decisão de compra com base na cor da carne são 3,327 maiores do que de um homem, bem como as chances de escolher uma carne pela menor quantidade de gordura são 4,293 maiores do que para a escolha de um homem. Já os atributos intrínsecos mais importantes foram a cor para 76,40\% dos consumidores com mais idadee $63,89 \%$ dos entrevistados com idade inferior a 40 anos, e a pouca quantidade de gordura para 69,66\% dos entrevistados com mais de 41 anos e 52,78\% dos consumidores com menos de 40 anos (Tabela 2).

Dentre os atributos e perspectivas analisados no fator socioeconômico idade, somente 34,23\% dos entrevistados com idade acima de 41 anos conhecem sobre a rastreabilidade. Porém, as chances de um consumidor com idade acima de 41 anos conhecerem sobre a rastreabilidade e carne com certificação são 1,879 vezes maior do que um indivíduo que tem menos de 40 anos (Tabela 2). 
Dos resultados associados à renda familiar, a maioria dos entrevistados com renda acima de sete salários mínimos (77,08\%) sabe o conceito correto de rastreabilidade como sendo aquele que traz informações relacionadas ao sistema de produção e origem do animal. As chances dos consumidores que tem maior renda saber o correto conceito de rastreabilidade são 4,399 vezes maiores do que os consumidores com renda abaixo de seis salários mínimos. Dos consumidores que têm maiores rendas, 81,25\% sabem que o conceito como sendo a carne que traz informações nutricionais no rótulo é incorreto.

Dos consumidores com renda mais baixa, 56,67\% acreditam que uma desvantagem da carne com certificação é que ela é mais cara do que a carne tradicional, por isso apenas 55,00\% está disposta a pagar mais caro pela carne rastreada contra 87,50\% dos consumidores com renda acima de sete salários mínimos. Tais consumidores têm 5,727 mais chances de pagar a mais pela carne com certificação do que os entrevistados que possuem menores rendas. No entanto, dentre os consumidores com renda mais baixa, que estão dispostos a pagar mais caro pela carne com certificação de origem, 36,36\% pagariam até 10\% a mais no preço atual, contra $16,67 \%$ dos consumidores com rendas mais altas (Tabela 3).

Quanto à escolaridade, neste estudo, apenas 39,16\% das pessoas que conhecem sobre carne rastreada ou com certificação de origem têm graduação ou pós-graduação, ao passo que os consumidores com escolaridade até o segundo grau completo, somente $25,54 \%$ deles conhecem sobre carne rastreada. Os entrevistados que possuem mais escolaridade têm 2,001 mais chances de já terem ouvido falar de carne rastreada, ou com certificação do que consumidores com menor nível de escolaridade (Tabela 4).

Pelo fato da maioria dos consumidores não conhecerem a carne com certificação, o conceito de rastreabilidade também não é bem conhecido. Para 81,35\% dos entrevistados com maior escolaridade e $63,08 \%$ dos consumidores com menor escolaridade, o conceito correto seria aquela fiscalizada pelo sistema de inspeção federal ou outra fiscalização do governo, o que não é verdadeiro. Outro conceito citado por alguns consumidores foi aquela que traz informações nutricionais no rótulo. Porém, pequena quantidade de pessoas indicou esse conceito como sendo o correto, ou seja, apenas 7,69\% dos consumidores graduados ou pós-graduados e 20,34\% dos entrevistados com até segundo grau completo. Os entrevistados com maior nível escolar têm

Tabela 3. Questões sobre o consumo de carne bovina por consumidores que conhecem o termo carne rastreada associadas à renda, em quatro supermercados do Rio de Janeiro, RJ, Brasil, em outubro de 2012.

\begin{tabular}{|c|c|c|c|c|c|c|c|}
\hline \multirow{2}{*}{ Questão levantada ${ }^{\mathrm{a}}$} & \multirow{2}{*}{ Renda } & \multicolumn{2}{|c|}{ Categorias de respostas } & \multirow{2}{*}{ Total } & \multirow{2}{*}{$\mathrm{p}$} & \multirow{2}{*}{ Odds Ratio } & \multirow{2}{*}{ IC (95\%) } \\
\hline & & Não & $\operatorname{Sim}(\%)$ & & & & \\
\hline \multirow{2}{*}{$\begin{array}{l}\text { Conceito de rastreabilidade: aquela que } \\
\text { traz informações relacionadas ao sistema } \\
\text { de produção e origem do animal }^{\mathrm{b}}\end{array}$} & $\leq 6$ salários mínimos & 34 & $26(43,34)$ & 60 & \multirow{2}{*}{0,001} & 1 & \multirow[t]{2}{*}{$1,890-10,238$} \\
\hline & 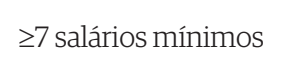 & 11 & $37(77,08)$ & 48 & & 4,399 & \\
\hline \multirow{2}{*}{$\begin{array}{l}\text { Conceito de rastreabilidade: aquela que } \\
\text { traz informações nutricionais no rótulo }\end{array}$} & 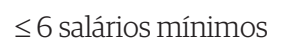 & 55 & $5(8,34)$ & 60 & \multirow{2}{*}{0,006} & 1 & \multirow[t]{2}{*}{$1,889-41,551$} \\
\hline & 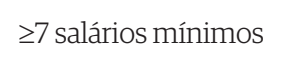 & 39 & $9(18,75)$ & 48 & & 8,860 & \\
\hline \multirow{2}{*}{$\begin{array}{l}\text { Benefícios da carne rastreada: acesso a } \\
\text { informações referentes a idade, sexo, raça } \\
\text { e outras caraterísticas do animal abatido }\end{array}$} & $\leq 6$ salários mínimos & 44 & $16(26,67)$ & 60 & \multirow[b]{2}{*}{0,024} & 1 & \multirow[t]{2}{*}{$1,131-5,659$} \\
\hline & >7 salários mínimos & 25 & $23(47,92)$ & 48 & & 2,530 & \\
\hline \multirow{2}{*}{$\begin{array}{l}\text { Desvantagens da carne com certificação: } \\
\text { produto mais carob }\end{array}$} & ×6 salários mínimos & 26 & $34(56,67)$ & 60 & \multirow{2}{*}{0,017} & 1 & \multirow[t]{2}{*}{$0,174-0,841$} \\
\hline & 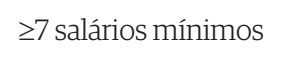 & 32 & $16(33,34)$ & 48 & & 0,382 & \\
\hline \multirow{2}{*}{$\begin{array}{l}\text { Disposição em pagar mais caro pela carne } \\
\text { bovina certificada }\end{array}$} & 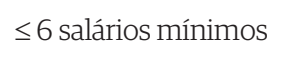 & 27 & $33(55,00)$ & 60 & \multirow{2}{*}{0,001} & 1 & \multirow[t]{2}{*}{$2,117-15,494$} \\
\hline & 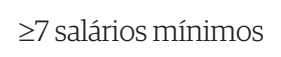 & 6 & $42(87,50)$ & 48 & & 5,727 & \\
\hline \multirow{2}{*}{$\begin{array}{l}\text { Disposto a pagar até } 10 \% \text { a mais pela } \\
\text { carne certificadac }\end{array}$} & 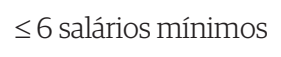 & 21 & $212(36,36)$ & 33 & \multirow{2}{*}{0,020} & 1 & \multirow[t]{2}{*}{$0,705-0,806$} \\
\hline & 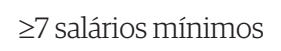 & 35 & $7(16,67)$ & 42 & & 0,246 & \\
\hline
\end{tabular}

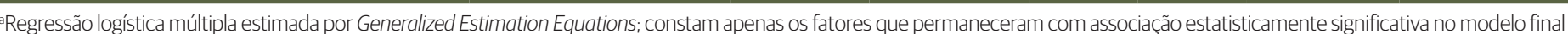

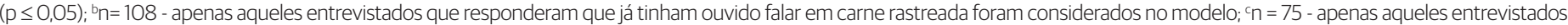
que responderam que estariam dispostos a pagar mais caro pela carne rastreada foram considerados no modelo. 
Tabela 4. Questões sobre o consumo de carne bovina por consumidores que conhecem o termo carne rastreada associadas à escolaridade, em quatro supermercados do Rio de Janeiro, RJ, Brasil, em outubro de 2012.

\begin{tabular}{|c|c|c|c|c|c|c|c|}
\hline \multirow{2}{*}{ Questão levantada ${ }^{a}$} & \multirow{2}{*}{$\begin{array}{l}\text { Escola- } \\
\text { Ridade }\end{array}$} & \multicolumn{2}{|c|}{$\begin{array}{l}\text { Categorias de } \\
\text { respostas }\end{array}$} & \multirow{2}{*}{ Total } & \multirow{2}{*}{$\begin{array}{l}\text { Valor } \\
\text { de p }\end{array}$} & \multirow{2}{*}{$\begin{array}{l}\text { Odds } \\
\text { Ratio }\end{array}$} & \multirow{2}{*}{ IC (95\%) } \\
\hline & & Não & $\operatorname{Sim}(\%)$ & & & & \\
\hline \multirow{2}{*}{$\begin{array}{l}\text { Já ouviu falar sobre carne rastreada ou com certificação de } \\
\text { origem }^{\text {b }}\end{array}$} & Até o $2^{\circ}$ grau & 172 & $59(25,54)$ & 231 & \multirow{2}{*}{0,004} & 1 & \multirow[t]{2}{*}{$1,242-3,221$} \\
\hline & 30grau ou mais & 101 & $65(39,16)$ & 166 & & 2,001 & \\
\hline \multirow{2}{*}{$\begin{array}{l}\text { Conceito de rastreabilidade: aquela fiscalizada pelo sistema } \\
\text { de inspeção federal ou outra fiscalização do governoc }\end{array}$} & Até o $2^{\circ}$ grau & 11 & $48(81,35)$ & 59 & \multirow{2}{*}{0,046} & 1 & \multirow[t]{2}{*}{ 0,181-0,986 } \\
\hline & 3ograu ou mais & 24 & $41(63,08)$ & 65 & & 0,422 & \\
\hline \multirow{2}{*}{$\begin{array}{l}\text { Conceito de rastreabilidade: aquela que traz informações } \\
\text { nutricionais no rótuloc }\end{array}$} & Até o $2^{\circ}$ grau & 47 & $12(20,34)$ & 59 & \multirow{2}{*}{0,006} & 1 & \multirow[t]{2}{*}{$0,025-0,545$} \\
\hline & 30grau ou mais & 60 & $5(7,69)$ & 65 & & 0,116 & \\
\hline \multirow{2}{*}{$\begin{array}{l}\text { Benefícios da carne rastreada: produtos com mais } \\
\text { qualidade, mais saborosos e nutritivos }{ }^{c}\end{array}$} & Até o $2^{\circ}$ grau & 29 & $30(50,85)$ & 59 & \multirow[t]{2}{*}{0,000} & 1 & \multirow[t]{2}{*}{$0,092-0,478$} \\
\hline & 30grau ou mais & 53 & $12(18,46)$ & 65 & & 0,210 & \\
\hline \multirow{2}{*}{ Motivo de tomada de decisão: raça do animalc } & Até o $2^{\circ}$ grau & 53 & $6(10,17)$ & 59 & \multirow{2}{*}{0,001} & 1 & \multirow[t]{2}{*}{$1,399-4,117$} \\
\hline & 30grau ou mais & 53 & $12(18,46)$ & 65 & & 2,400 & \\
\hline
\end{tabular}

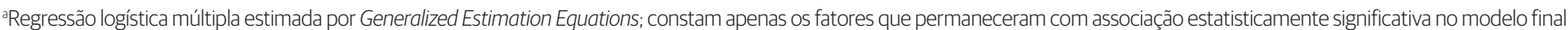
$(p \leq 0,05) ;{ }^{b} n=397$ - entrevistados; ${ }^{c} n=124$ - apenas aqueles entrevistados que responderam que já tinham ouvido falar em carne rastreada foram considerados no modelo.

0,422 menor chance de acharem que o conceito correto de rastreabilidade é a carne que tem fiscalização do governo e 0,116 menor chance de achar que o conceito correto é a carne que traz informações nutricionais no rótulo do que consumidores que possuem menor nível de escolaridade (Tabela 4).

\section{Discussão}

Neste estudo, foi demonstrado que o sexo está associado a diversas atitudes e percepções dos consumidores com relação à carne bovina com certificação de origem. Assim, indivíduos do gênero masculino demonstraram maior conhecimento sobre o termo carne com rastreabilidade, uma vez que $41,7 \%$ destes já tinham ouvido falar em carne rastreada, enquanto apenas $25,1 \%$ dos indivíduos de gênero feminino conheciam este tipo de produto. Do percentual de homens que conhecem carne bovina rastreada, ou com certificação de origem, 50,00\% deles consomem produtos animais com certificação de origem (Tabela 1). Diferente do que foi encontrado neste estudo, Gellynck et al. (2006), ao avaliar os efeitos da percepção de segurança alimentar por meio da rotulagem pelos consumidores belgas, encontraram que 50,00\% dos entrevistados relataram ter conhecimento sobre a rastreabilidade; dos outros 50,00\% dos participantes da pesquisa, 15,00\% indicaram ter um conhecimento muito pobre sobre o assunto e 35,00\% disseram não saber realmente o que é a rastreabilidade. Velho et al. (2009), em uma pesquisa com 111 consumidores de carne bovina na cidade de Porto Alegre, RS, constataram que uma maior porcentagem de mulheres (50,90\%) preferem que a carne tenha certificado de origem, contra 41,40\% dos homens, o não condiz com os resultados deste trabalho, pois foram os homens que deram maior preferência ao consumo de produtos com certificação.

A minoria (10,29\%) dos homens e 29,82\% das mulheres entenderam ser o conceito correto de rastreabilidade a carne que não possui contaminantes ou resíduos químicos. As mulheres entrevistadas, nesta pesquisa, têm 3,486 mais chances do que os homens de acharem que o conceito correto de rastreabilidade é a carne que não possuem contaminantes ou resíduos químicos (Tabela 1). O que pode ser observado é que, apesar da maioria dos consumidores não saberem o significado correto de rastreabilidade, eles pelo menos têm a consciência de que o conceito adequado também não é a carne livre de contaminantes e resíduos.

A desvantagem relatada por $43,86 \%$ das mulheres é que a carne com certificação acarreta uma supervalorização, podendo causar o aumento dos preços da carne nos mercados ou a falta do produto nas prateleiras. Foi constatado que os homens (33,34\%) estão dispostos a pagar até 
10\% a mais pela carne com certificação de origem. As chances dos entrevistados do sexo feminino acharem que uma desvantagem de carne certificada é sua supervalorização são 2,539 vezes maiores do que os homens; com isso, a chance das mulheres pagarem até $10 \%$ a mais pela carne certificada é menor $(0,243)$ do que a disposição dos homens pagarem esse valor a mais pela carne certificada (Tabela 1).

Verbeke et al. (2010) observaram que os consumidores estariam dispostos a pagar mais pelo produto se os cortes de carne bovina fossem de alta qualidade. Porém, alguns consumidores se declararam preocupados sobre a questão da implementação de um sistema de garantia muito sofisticado. O receio é que se elevassem muito os custos com a produção de carne, e concordam que a aplicação de controles rígidos na produção aumentariam os custos enormemente, e que assim não conseguiriam pagar a mais para comer um produto de qualidade.

A desvantagem da carne com certificação ser considerada mais cara pode ser melhorada se esse produto realmente garantir que irá trazer consigo o acréscimo de algum benefício em relação à carne tradicional, como citado por Dickinson \& Von Bailey (2005), Loureiro \& Umberger (2007) e Velho et al. (2009), ao salientarem que os consumidores estariam dispostos a pagar um valor maior do que o habitual pela carne com certificação se houvessem garantias adicionais de segurança alimentar, combinados com a rastreabilidade. Para Hobbs et al. (2005), a disposição em pagar mais pela carne está intimamente ligada a algum aspecto que denote segurança alimentar e não por sua característica física ou organoléptica. Foi observado, por Verbeke et al. (2010), que os consumidores prestam bastante atenção aos preços, e alguns participantes indicaram que estariam dispostos a pagar a mais somente se os cortes de carne bovina fossem de alta qualidade.

Os consumidores do sexo masculino (33,34\%) e 16,67\% das mulheres estão dispostos a pagar até $10 \%$ a mais pela carne certificada, ou seja, a maioria desses consumidores não estão dispostos a pagar a mais pela carne com certificação de origem; ao contário de Zhao et al. (2010), ao relatarem que a maioria dos seus entrevistados pagariam 9 a $12 \%$ a mais por produtos rastreados. Verbeke et al. (2007) observaram que o preço que o consumidor tende a aceitar também depende da acessibilidade ao produto; o preço pago pelo consumidor está relacionado com a sua disponibilidade no mercado.

Os resultados deste estudo não corroboram com os de Verbeke \& Ward (2006) e Van Wezemael et al. (2010), ao afirmarem que na percepção dos consumidores avaliados a carne mais barata é declarada menos segura. Isso está relacionado com o fato de que, para a maioria dos consumidores, a qualidade de um produto está intimamente ligada ao seu preço, ou seja, o queé mais caro tem mais qualidade. Segundo Angulo \& Gil (2007), em estudo realizado na Espanha, o preço é um dos fatores mais importantes na percepção do risco de segurança alimentar e que os consumidores acreditam que produtos mais caros apresentam algum tipo de vantagem.

Dentre os atributos e perspectivas analisados no fator socioeconômico idade, somente 34,23\% dos entrevistados com idade acima de 41 anos conhecem sobre a rastreabilidade. Porém, as chances de um consumidor com idade acima de 41 anos conhecerem sobre a rastreabilidade e carne com certificação são 1,879 vezes maior do que um indivíduo que tem menos de 40 anos (Tabela 2). O baixo conhecimento sobre a rastreabilidade, ainda que este estudo tenha sido realizado em supermercados que comercializam carne com certificação de origem, pode ser explicado por Schnettler et al. (2009), Verbeke \& Ward (2006) e Zhao et al. (2010), pela falta de interesse do consumidor, ou a falta de familiaridade com produtos certificados. Barcellos et al. (2012), de um total de 417 entrevistados em cidades do estado do Rio Grande do Sul, com predominância de consumidores de Porto Alegre, RS, verificaram que 54,70\% estavam cientes sobre o sistema de rastreabilidade de carne bovina brasileira (SISBOV). No entanto, uma parte significativa dos consumidores ainda não está ciente do SISBOV, o que pode ser explicado pela falta de mecanismos institucionais para informar o público sobre rastreabilidade, resultado que pode esclarecer o encontrado neste estudo.

As caraterísticas extrínsecas do rótulo eintrínsecas da carne bovina são motivos determinantes para a tomada de decisão no momento da compra. Os atributos intrínsecos mais importantes foram a cor para 76,40\% dos consumidores com mais idade e 63,89\% dos entrevistados com idade inferior a 40 anos, e a pouca quantidade de gordura para 69,66\% dos entrevistados com mais de 41 anos e $52,78 \%$ dos consumidores com menos de 40 anos. Assim como nesta pesquisa, para Velho et al. (2009) e Barcellos et al. (2012) o atributo que mais determina a compra de carne 
bovina pelos consumidores é a cor. Verbeke \& Ward (2006) salientaram que o atributo cor pode ser sugerido como indicação de segurança e qualidade de carne, ao passo que a carne embalada com materiais opacos foi percebida como menos segura, uma vez que esses tipos de embalagens não permitem que os consumidores avaliem esse atributo. Pela mesma razão, alimentos frescos foram percebidos como bastante seguros.

Van Wezemael et al. (2010), avaliando as informações de segurança alimentar como processos decisórios da compra de carne bovina, em quatro países europeus, mostraram que várias informações intrínsecas foram mencionadas pelos participantes, como sendo um sinal de segurança alimentar, como cor, textura e teor de gordura, assumindo que o aspecto do produto é também uma pista de que ele é seguro. Schnettler et al. (2010a), ao avaliarem a importância dos atributos intrínsecos para 400 consumidores na cidade de Temuco, Chile, salientaram que o teor de gordura $(64,8 \%)$ e cor $(62,6 \%)$ eram atributos mais importantes do que o preço da carne bovina.

A característica extrínseca mais valorizada pelos consumidores com idades acima de 41 anos (53,93\%) é o local onde o animal foi abatido (frigorífico) (Tabela 2). A escolha por esse atributo pode ser explicada pelo fato dos consumidores confiarem que esses locais são responsáveis pela segurança do produto que eles irão consumir, assim como observa Van Wezemeal et al. (2010), ao afirmarem que, na visão dos consumidores, a responsabilidade pela segurança da carne deve ser dada às pessoas que estão situadas no início da cadeia de produção de carne bovina. As boas condições em que os animais nascem, crescem e são abatidos precedem um produto seguro. Portanto, agricultores, veterinários, agentes de inspeção e frigoríficos, assim como os estabelecimentos de venda dos produtos, foram responsáveis pela segurança em primeiro lugar.

Dos resultados associados à renda familiar, a maioria dos entrevistados com renda acima de sete salários mínimos (77,08\%) sabe o conceito correto de rastreabilidade como sendo aquele que traz informações relacionadas ao sistema de produção e origem do animal. As chances dos consumidores que tem maior renda saber o correto conceito de rastreabilidade são 4,399 vezes maiores do que os consumidores com renda abaixo de seis salários mínimos. Dos consumidores que têm maiores rendas, 81,25\% sabem que o conceito como sendo a carne que traz informações nutricionais no rótulo éincorreto. Assim como a maioria dos consumidores com maiores rendas, desta pesquisa, sabem o que é carne rastreada, 70,50\% dos entrevistados da pesquisa de Barcellos et al. (2012), também conhecem a rastreabilidade. Ainda, a maioria desses entrevistados (62,40\%) disse que era a favor da rastreabilidade de carne obrigatória no Brasil, sugerindo a tendência que os consumidores exigem cada vez mais que a carne seja rastreada; $86,60 \%$ discordaram com o destino exclusivo da carne rastreada para o mercado externo, porque eles querem esse tipo de carne disponível no mercado nacional.

Para 47,92\% dos consumidores com renda mais alta, o benefício da carne com certificação de origem é que ela dá acesso a informações referentes a idade, sexo, raça e outras caraterísticas do animal abatido. Schnettler et al. (2009) e Verbeke \& Ward (2006), em seus estudos no Chile e na Bélgica, sobre o significado do termo rastreabilidade, mostraram que os consumidores têm baixo interesse em obter informações sobre rastreabilidade, o que não aconteceu neste estudo, pois como a maioria dos consumidores com renda mais alta sabem o que érastreabilidade, eles também veem como benefício saber a origem da carne. Os indivíduos com melhores rendas familiares demostraram que a rastreabilidade é um atributo de importância relevante no momento da compra; o contrário foi observado pelos consumidores da pesquisa de Schnettler et al. (2010b) , ao constatarem que somente $27,5 \%$ de consumidores chilenos consideram importante o tratamento dos animais antes do abate, região de origem e sistema de rastreabilidade.

Próximo aos resultados encontrados sobre a disposição em se pagar mais pela carne com certificação dos consumidores com renda mais baixa deste estudo, Ortega et al. (2011), avaliando consumidores chineses sobre a percepção de segurança alimentar da carne suína, observaram que 38,00\% dos consumidores estão preocupados com a segurança da carne que compram e estão dispostos a pagar um valor adicional para assegurar que os alimentos sejam seguros. Foi ressaltada que a disposição em se pagar mais por informações de segurança alimentar aumenta na mesma medida em que o consumidor se sente ameaçado com riscos de insegurança alimentar.

Velho et al. (2009) constataram que 68,00\% dos consumidores estariam dispostos a pagar até $10 \%$ a mais sobre o valor da carne. Neste trabalho, somente $36,36 \%$ estariam dispostos a isso. Também, diferente do encontrado neste estudo, uma porcentagem bem abaixo de consumidores 
estariam dispostos a pagar a mais pela carne com certificação foi encontrada nos estudos de Schnettler et al. (2010a), no qual a minoria (18,5\%) dos consumidores pagariam um preço mais elevado pela carne que trouxesse a característica intrínseca da qual desejavam; e, para Gellyncket al. (2006),10\% dos entrevistados estariam dispostos a pagar um valor a mais pela carne que tivesse no rótulo a informação de carne com certificação de origem.

Os entrevistados que possuem mais escolaridade têm 2,001 mais chances de já terem ouvido falar de carne rastreada, ou com certificação do que consumidores com menor nível de escolaridade (Tabela 4). Esses resultados confirmam os encontrados por Gellynck et al. (2006), ao afirmarem que enquanto as pessoas com mais escolaridade $(70,00 \%)$ relataram saber bem, ou muito bem, sobre a rastreabilidade, somente $44,00 \%$ das pessoas com baixa escolaridade afirmaram conhecer sobre a rastreabilidade. Segundo esses pesquisadores, os resultados demonstraram que a maior dificuldade em se ouvir falar da carne rastreada diz respeito à falta de disponibilidade e acessibilidade de informações desse produto. A disponibilidade limitada de informações faz com que os consumidores sejam prejudicados, pois fazem suas escolhas com base no seu próprio conhecimento e opiniões e não com base nas informações do rótulo.

Pelo fato da maioria dos consumidores não conhecerem a carne com certificação, o conceito de rastreabilidade também não é bem conhecido. Outro conceito citado por alguns consumidores foi aquela que traz informações nutricionais no rótulo. Porém, pequena quantidade de pessoas indicou esse conceito como sendo o correto, ou seja, apenas 7,69\% dos consumidores graduados ou pós-graduados e 20,34\% dos entrevistados com até segundo grau completo. Os entrevistados com maior nível escolar têm 0,422 menor chance de acharem que o conceito correto de rastreabilidade é a carne que tem fiscalização do governo e 0,116 menor chance de achar que o conceito correto é a carne que traz informações nutricionais no rótulo do que consumidores que possuem menor nível de escolaridade (Tabela 4). Esses resultados são semelhantes aos encontrados por Barcellos et al. (2012), ao verificarem que 70,50\% dos consumidores são conhecedores dos selos de qualidade como SIF, CISPOA, SIM. Além da rastreabilidade não ser conhecida pelos consumidores, percebeu-se ainda que ela raramente foi considerada (3,40\%) como um atributo de qualidade da carne pelos entrevistados. Resultados semelhantes foram observados por Zhao et al. (2010), em uma entrevista a 588 pessoas nas cidades de Beijing e Xianyang, na China, ao mostrarem que apenas $3,00 \%$ dos entrevistados estavam familiarizados com o conceito correto de rastreabilidade. Um dos fatores que contribuiu para o baixo índice de familiaridade na China, segundo esses autores, é o fato de que a rastreabilidadeé recente naquele país, sendo que as primeiras importações foram realizadas em 2009.

Apesar do conceito de rastreabilidade não ser bem conhecido para os entrevistados, o conceito que eles escolheram traz uma impressão de segurança extra do produto, assim como relataram Schnettler et al. (2009), em pesquisa realizada com 770 consumidores em Bío-Bío e La Araucanía, no Chile, quando observaram alto nível de concordância sobre a inclusão de um selo de garantia de qualidade no rótulo da carne. Pois, embora o regulamento daquele país sobre a produção de alimentos defina procedimentos obrigatórios para assegurar a qualidade do produto, estas informações não são bem conhecidas pelos consumidores. E, consequentemente, um selo fornecido pelo serviço de inspeção federal, ou um órgão encarregado de fazer cumprir as normas estabelecidas nas leis, aumentaria a confiança do consumidor no produto. Os resultados desses autores indicam que os consumidores não necessitam de informações técnicas e preferem informações de fácil e rápida interpretação, como por exemplo, um selo, demostrando que a aquela carne é rastreada.

Loureiro \& Umberger (2007), ao analisarem as preferências dos consumidores norte-americanos de carne bovina, concluíram que, apesar das informações relacionadas à rastreabilidade e origem da carne serem informações altamente importantes para os consumidores, o atributo que mais entrevistados associaram como sendo um alimento seguro eram aqueles que continham, no rótulo, uma garantia de que a carne foi inspecionada por algum órgão governamental ligado a segurança alimentar, sendo considerada mais segura do que os atributos de rastreabilidade. A explicação desses consumidores não saberem o conceito correto de rastreabilidade pode ser dada pelo fato de que o indivíduo não tendo conhecimento sobre a rastreabilidade, o mais perto que se pode equiparar-se como sendo um alimento seguro é aquela que possui uma fiscalização do governo. 
A raça do animal praticamente não foi levada em consideração como tomada de decisão da compra, pois somente 10,17\% dos consumidores com até segundo grau e 18,46\% com maior nível de escolaridade levaram esse atributo em consideração (Tabela 4). Bernués et al. (2003) constataram que os consumidores têm opiniões confusas com relação a raça do animal, pois apesar de saberem que esse atributo pode contribuir para a determinação de um produto diferenciado na maciez e deposição de gordura, quando avaliado como um atributo de credibilidade, seu mérito é extremamente baixo. Um dos benefícios citados por 50,85\% dos consumidores com menor escolaridade é que a carne rastreada tem mais qualidade, é mais saborosa e nutritiva.

Para Van Wezemael et al. (2010), a carne rastreada proporciona segurança e qualidade mesmo sobre uma carne de marca desconhecida. Os consumidores avaliados por Cunha et al. (2011) afirmaram que os produtos com garantia de origem são mais confiáveis, têm mais qualidade, tem mais frescor. No entanto, nos estudos de Barcellos et al. (2012), a rastreabilidade raramente foi considerada (3,40\%) como um crédito de certificação de qualidade de carne pelos entrevistados.

Para Schnettler et al. (2009), é necessário se fazer campanhas informativas para incentivar a leitura dos rótulos das embalagens de carne, para que os consumidores saibam os benefícios de se consumir carne com garantia de origem, pois os rótulos armazenam informações que podem assegurar a qualidade dos produtos aos consumidores, fazendo com que eles se sintam mais confiáveis e seguros em consumir tais alimentos.

\section{Conclusôes}

Os fatores socioeconômicos influenciaram a disposição dos consumidores do Rio de Janeiro em adquirir carne bovina com certificação de origem. A maioria dos entrevistados nunca ouviu falar sobre carne bovina rastreada ou com certificação de origem. O conceito correto de rastreabilidade é conhecido pela maioria dos consumidores com maiores rendas. Os entrevistados estão dispostos a comprar carne rastreada, sendo em sua maioria consumidores com renda acima de sete salários mínimos; e estão dispostos a pagar até $5 \%$ a mais por esse produto. Os entrevistados acreditam que o maior benefício da carne rastreada é oferecer mais segurança e evitar riscos de doenças transmitidas pelos alimentos; e, a desvantagem é ser um produto mais caro do que o convencional. Os atributos intrínsecos mais importantes na tomada de decisão da carne no momento da compra foram o odor, a maciez, a cor e a pouca quantidade de gordura; enquanto que os atributos extrínsecos mais importantes foram o carimbo do SIF, o preço e o selo de qualidade.

\section{Referências}

Angulo, A. M., \& Gil, J. M. (2007). Risk perception and consumer willingness to pay for certified beef in Spain. Food Quality and Preference, 18(8), 1106-1117. http://dx.doi.org/10.1016/j.foodqual.2007.05.008.

Associação Brasileira das Indústrias Exportadoras de Carnes. (2011). Mapa das plantas frigoríficas, exportadores. São Paulo: ABIEC. Recuperado em 15 de julho de 2012, de http://www.abiec.com.br/2_mapa.asp

Barbetta, P. A. (2007). Estatística aplicada às Ciências Sociais (7ª ed., 315 p.). Florianópolis: UFSC.

Barcellos, J. O. J., Abicht, A. M., Brandão, F. S., Canozzi, M. E. A., \& Collares, F. C. (2012). Consumer perception of Brazilian traced beef. Revista Brasileira de Zootecnia, 41(3), 771-774. http://dx.doi.org/10.1590/S1516-35982012000300041.

Bernués, A., Olaizola, A., \& Corcoran, K. (2003). Labelling information demanded by European consumers and relationships with purchasing motives, quality and safety of meat. Meat Science, 65(3), 1095-1106. http:// dx.doi.org/10.1016/S0309-1740(02)00327-3. PMid:22063692.

Cunha, C. F., Spers, E. E., \& Zylbersztajn, D. (2011). Percepção sobre atributos de sustentabilidade em um varejo supermercadista. Revista de Administração de Empresa, 51(6), 542-552. http://dx.doi.org/10.1590/ $\underline{\text { S0034-75902011000600004. }}$

Dickinson, D. L., \& Von Bailey, D. (2005). Experimental evidence on willingness to pay for red meat traceability in the United States, Canada, the United Kingdom, and Japan. Journal of Agricultural and Applied Economics, 37(03), 537-548. http://dx.doi.org/10.1017/S1074070800027061.

Furquim, N. R., \& Cyrillo, D. C. (2012). Food production chain identification and traceability systems: an analysis considering the perspective of a safe beef offer (55 p.). São Paulo: USP.

Gellynck, X., Verbeke, W., \& Vermeire, B. (2006). Pathways to increase consumer trust in meat as a safe and whole some food. Meat Science, 74(1), 161-171. http://dx.doi.org/10.1016/j.meatsci.2006.04.013. PMid:22062725.

Hanley, A. J., Negassa, A., Edwardes, M. D. B., \& Forrester, J. E. (2003). Statistical analysis of correlated data using generalized estimating equations: an orientation. American Journal of Epidemiology, 157(4), 364-375. http:/l dx.doi.org/10.1093/aje/kwf215. PMid:12578807. 
Hobbs, J. E., Bailey, D., Dickinson, D. L., \& Haghiri, M. (2005). Traceability in the Canadian red meat sector: do consumers care? Canadian Journal of Agricultural Economics, 53(1), 47-65. http://dx.doi.org/10.1111/j.1744-7976.2005.00412.x.

Instituto Brasileiro de Geografia e Estatística. (2010).Cidades@: Rio de Janeiro. Rio de Janeiro: IBGE. Recuperado em 27 de maio de 2012, de http://www.ibge.gov.br/cidadesat/topwindow.htm?1

Lopes, M. A., \& Santos, G. (2007). Principais dificuldades encontradas pelas certificadoras para rastrear bovinos. Ciência e Agrotecnologia, 31(5), 1552-1557. http://dx.doi.org/10.1590/\$1413-70542007000500042.

Lopes, M. A., Pacheco, E. O., Bruhn, F. R. P., Vicente, F. H., Faria, P. B., \& Rocha, C. M. B. M. (2014). Fatores associados à percepção e atitudes de consumidores de carne bovina com certificação de origem. Revista Brasileira de Ciência Veterinária, 21(2), 131-136. http://dx.doi.org/10.4322/rbcv.2014.037.

Loureiro, M. L., \& Umberger, W. J. (2007). A choice experiment model for beef: what us consumer responses tell us about relative preference of food safety, country-of-origin labeling and traceability. Food Policy, 32(4), 496-514. http://dx.doi.org/10.1016/j.foodpol.2006.11.006.

Ortega, D. L., Wang, H. H., Wu, L., \& Olynk, N. J. (2011). Modeling heterogeneity in consumer preferences for select food safety attributes in China. Food Policy, 36(2), 318-324. http://dx.doi.org/10.1016/j.foodpol.2010.11.030.

Schnettler, B., Ciesla, M., Candia, A., Llancanpan, F., Sepulveda, J., Denegri, M., Miranda, H., \& Sepulveda, N. (2010a). Importancia del color, contenido de grasa y frescura en la compra de la carne bovina en Temuco, Region de La Araucania, Chile. Revista Científica de la Facultad de Ciencias Veterinarias, 20, 623-632.

Schnettler, B., Fica, D., Sepulveda, N., Sepulveda, J., \& Denegri, M. (2010b). Valoracion de atributos intrinsecos y extrinsecos en la compra de la carne bovina en el sur de Chile. Revista Científica de la Facultad de Ciencias Veterinarias, 20, 101-109.

Schnettler, M. B., Silva, F. R., \& Sepúlveda, B. N. (2009). Utility to consumers and consumer acceptance of information on beef labels in southern Chile. Chilean Journal of Agricultural Research, 69(3), 373-382. http:// dx.doi.org/10.4067/S0718-58392009000300010.

Van Wezemael, L., Verbeke, W., Kügler, J. O., \& Barcellos, M. D., \& Grunert, K. G. (2010). European consumers and beef safety: Perceptions, expectations and uncertainty reduction strategies. Food Control, 21(6), 835-844. http://dx.doi.org/10.1016/j.foodcont.2009.11.010.

Velho, J. P., Barcellos, J. O. J., Lengler, L., Elias, S. A., \& Oliveira, T. E. (2009). Disposição dos consumidores portoalegrenses à compra de carne bovina com certificação. Revista Brasileira de Zootecnia, 38(2), 399-404. http:// dx.doi.org/10.1590/S1516-35982009000200025.

Verbeke, W., \& Ward, R. W. (2006). Consumer interest in information cues denoting quality, traceability and origin: an application of ordered probit models to feed labels. Food Quality and Preference, 17(6), 453-467. http://dx.doi.org/10.1016/j.foodqual.2005.05.010.

Verbeke, W., Frewer, L. J., Scholderer, J., \& De Brabander, H. F. (2007). Why consumers behave as they do with respect to food safety and risk information. Analytica Chimica Acta, 586(1-2), 2-7. http://dx.doi.org/10.1016/j. aca.2006.07.065. PMid:17386689.

Verbeke, W., Van Wezemael, L., Barcellos, M. D., Kügler, J. O., Hocquette, J.-F., Ueland, Ø., \& Grunert, K. G. (2010). European beef consumers' interest in a beef eating-quality guarantee Insights from a qualitative study in four EU countries. Appetite, 54(2), 289-296. http://dx.doi.org/10.1016/j.appet.2009.11.013. PMid:19961887.

Zhao, R., Qiao, J., \& Chen, Y. (2010). Influencing factors of consumer willingness-to-buy traceable foods: an analysis of survey data from two Chinese cities. Agriculture and Agricultural Science Procedia, 1, 334-343. http://dx.doi.org/10.1016/j.aaspro.2010.09.042. 